\title{
Identidade e Identificação - Um Estudo sobre a Publicidade e seus Reflexos Sociais
}

\author{
Eric Anacleto Ribeiro ${ }^{1}$
}

\section{Resumo}

"O que o produto tem? O que o produto faz? O que você sente? Quem você é?"2 A sequência de perguntas sintetiza objetivamente a evolução na forma em que os profissionais de marketing trabalham (ou deveriam trabalhar) suas marcas, produtos e/ou serviços em diferentes épocas, conforme as transformações sociais, como sugerem alguns estudiosos da área, ao exemplo de Marty Neumeier. Por volta de 1900, a publicidade, uma das ferramentas do marketing de maior interação social, tinha por finalidade elucidar aspectos tangíveis e características físicas de determinado objeto; 100 anos mais tarde, o foco parece ter deixado tal objeto e se dirigido ao seu potencial usuário, às suas aspirações enquanto ser social e indivíduo singular carente de identidade.

Este trabalho teve a pretensão de discutir essa evolução e propor uma reflexão acerca do foco comunicacional - como parte de um processo - que trouxe prestígio e sucesso para determinadas empresas, produtos e marcas, estabelecendo uma relação satisfatória com seus públicos, seja pela identificação ou identidade. Para ganhar a atenção do consumidor na contemporaneidade do século XXI, a publicidade dialoga com o emocional e com as aspirações do indivíduo (quem você é?) - identidade; ou constrói um relacionamento por meio de um alinhamento consciente de necessidades,

\footnotetext{
1 eric.anacleto@gmail.com / (11) 97027-9886. Vínculo atual: UNIFESP / Graduação em Ciências Sociais. Orientador: Prof. Titular Mitsuru Higuchi Yanaze - ECA/USP.

2 NEUMEIER, 2006, p. 38
} 
expectativas e potenciais da organização emissora e do segmento de mercado almejado - identificação.

\section{O Universo da Comunicação}

Frequentemente, ouvimos dizer que a comunicação é a simples transmissão de informação através de um sistema de coordenação consensual: a língua. Restrita à concepção de simples mensagens enviadas por um agente consciente a outro, a característica essencial da comunicação ficou relegada somente ao ato da fala com a finalidade de simples troca de recados. Porém, mais do que isso, o ato de comunicar está ligado à necessidade humana de manter contato com o seu meio, de entender o mundo ao seu redor e de se fazer entender por ele $^{3}$. Através da comunicação, estamos sempre influenciando o meio em nossa volta e sendo influenciados por ele ${ }^{4}$, pois, queiramos ou não, a sociedade está sempre interagindo conosco, moldando a nossa percepção e ação, reforçando ou desaprovando comportamentos.

O marketing possui papel fundamental nesse organismo social regido pela linguagem. Segundo o filósofo francês Gilles Lipovetsky, o consumo (objetivo final do marketing) é um dos "raros fenômenos que conseguiram modificar profundamente os modos de vida, os gostos, as aspirações e os comportamentos da maioria, em um intervalo de tempo tão curto" ${ }^{5}$. Isso porquê, é através do consumo que as pessoas satisfazem suas necessidades e é por meio da persuasão ao consumo que novas necessidades são impulsionadas, como, por exemplo, a tecnologia de dispositivos móveis de telecomunicação: a necessidade de se comunicar sempre existiu, porém, coube, principalmente, ao marketing expandir cada vez mais as possibilidades dessa interação. E, assim, surgiram o pager, o celular, o tablet,

\footnotetext{
${ }^{3}$ WITTGENSTEIN, 2005.

${ }^{4}$ Ibid.

${ }^{5}$ LIPOVETSKY, 2006, p. 8
} 
o smartphone. É possível notar que o desenvolvimento de tais produtos acompanhou e, ao mesmo tempo, influenciou a sociedade e suas aspirações.

\section{Identidade e Identificação}

Sendo a pós-modernidade um contexto social novo, ela produz um novo sujeito, cuja identidade não se restringe a uma só definição, e o próprio ambiente social contemporâneo fornece aparatos para uma múltipla experiência subjetiva e social. Hall nos ensina que:

"A identidade é formada na interação entre o eu e a sociedade. $O$ sujeito ainda tem um núcleo ou essência interior que éo "eu real", mas este é formado e modificado num diálogo contínuo com os mundos culturais "exteriores" e as identidades que os mundos oferecem" 6 .

Ainda segundo Hall:

"A identidade nessa concepção sociológica preenche o espaço entre o 'interior' e o 'exterior' - entre o mundo pessoal e o mundo público. (...) $O$ sujeito previamente vivido como tendo uma identidade unificada e estável, está se tornando fragmentado; composto não de uma única, mas de várias identidades, algumas vezes contraditórias ou não resolvidas (...) à medida que os sistemas de significação cultural se multiplicam, somos confrontados por uma multiplicidade desconcertante e cambiante de identidades possiveis, com cada uma das quais poderíamos nos identificar - ao menos temporariamente. "7

A ideia vai ao encontro da afirmativa de Serres, na qual a identidade pode ser compreendida como uma complexa formação em permanente redefinição, uma "multiplicidade de experiências e jogos relacionais, dos

\footnotetext{
6 HALL, 2001, p. 11

7 HALL, 2001, p. 12, 13
} 
quais os sujeitos participam e que os posicionam na situação de viver simultaneamente múltiplas pertinências". 8 Assim, a construção de identidades, concebida como um processo histórico, social e politicamente negociado, remete à premissa básica de sua produção e reprodução no interior das relações da sociedade contemporânea, estruturando posições sociais ocupadas por homens e mulheres de forma desigual e hierárquica.

De acordo Woodward, "as formas pelas quais a cultura estabelece fronteiras e distingue a diferença são cruciais para compreender as identidades. A diferença é aquilo que separa uma identidade de outra, estabelecendo distinções, frequentemente na forma de oposições"'. Nesse sentido, buscando manter a ordem social os membros de uma sociedade acabam por possuir certo grau de consenso acerca de como classificar as coisas. Isso, segundo a autora, é o que se entende por cultura que, na forma de rituais, símbolos e classificações, é fundamental para a produção do significado e das relações sociais.

É sabido, portanto, que a construção de nossa identidade é um processo, ao mesmo tempo, autônomo e relacional, pois depende do reconhecimento e da estima alheia. A identidade é formada interativamente, e ganha a forma de uma narrativa coerente ${ }^{10}$ a partir de nossas experiências intersubjetivas marcadas por construções simbólicas que envolvem relações de poder. Dentro dessa rede construtiva, a comunicação de marketing, para aumentar seu poder persuasivo e assumir um tom mais natural, busca se vincular a determinadas identidades, as quais caracterizam segmentos de mercado, como iremos perceber posteriormente em um exemplo da marca Harley Davidson.

\footnotetext{
${ }^{8}$ SERRES, 1995, p. 171

9 Ibid., p. 41

10 HALL, 2001.
} 
Percorrida, pelo menos em parte, a discussão acerca das identidades, podemos focar nossos esforços a outro item de caracterização social: a identificação. Para os fins desse trabalho, entendemos identificação como tudo aquilo que preenche no indivíduo uma necessidade racional e objetiva. Nesse sentido, podemos entender identificação como um processo constituinte da identidade, porém em menor complexidade e, supostamente, com diferente apelo comunicacional. A marca Honda, que também iremos analisar em exemplo posterior, dialoga com o consumidor e busca ganhar sua atenção e preferência, assim como sua concorrente já citada. Percebemos, entretanto, que, para isso, a peça publicitária escolhe mostrar a esse consumidor que o produto está apto a satisfazer suas necessidades e, dessa forma, fazer com que ele se identifique com o produto, o que é diferente de assumir uma identidade. Deparamo-nos com dois modelos estratégicos totalmente distintos e que, apesar do que defende Neumeier, nenhum parece conseguir se sobrepor em relação ao outro quando o número de vendas é analisado. A sociedade parece estar em um estágio no qual a identidade e a emoção ganham mais e mais força; por outro lado, como entender - por exemplo - que uma comunicação que não segue à risca essa tendência pode trazer resultado? Tomamos o exemplo das Casas Bahia: a empresa é a maior anunciante do país (Brasil) ${ }^{11}$, presente há mais de 50 anos no mercado, com mais de 56 mil colaboradores e mais de 500 filiais presentes em 13 estados $^{12} \mathrm{e}$, principalmente, é conhecida por suas campanhas extremamente vinculadas a preço e benefícios tangíveis.

Isso nos traz a reflexão de que o maior desafio do marketing não é, necessariamente, dialogar diretamente e de forma explícita com a identidade do consumidor, mas sim ir afundo e entender quais são suas reais

\footnotetext{
11 O Ranking dos Maiores Anunciantes

12 Site corporativo
} 
necessidades, potenciais e expectativas, assim como demanda; e, a partir daí, alinhá-las com os outputs da organização para, somente após esse profundo mapeamento, definir a melhor forma de conversar com o segmento de mercado. Devemos sempre nos lembrar que o consumidor pode querer se sentir parte de uma tribo, ser julgado pelo o que usa e consome, mas ao mesmo tempo também pode querer adequar suas compras ao seu potencial financeiro e às suas necessidades diárias.

\section{A Publicidade e a Linguagem Publicitária}

A publicidade, como todo ato de comunicação, é engendrada para cumprir uma função utilitária: persuadir um auditório particular. ${ }^{13}$ De acordo com o repertório desse auditório, a publicidade pode fazer uso de diferentes roupagens para cumprir sua função e atingir da melhor maneira possível seu público, não somente alimentando o sistema proposto por Lipovetsky, mas também refletindo a sociedade que a tangencia.

Tendo isso em vista, nas campanhas publicitárias, ora nos deparamos com peças que buscam dialogar com a identidade de seus consumidores, ora também notamos peças que, antes disso, buscam gerar identificação por compartilhar atributos tangíveis desejáveis, que satisfazem as necessidades de determinado segmento de mercado. Vejamos os dois exemplos a seguir:

${ }^{13}$ CARRASCOZA, 2004. 


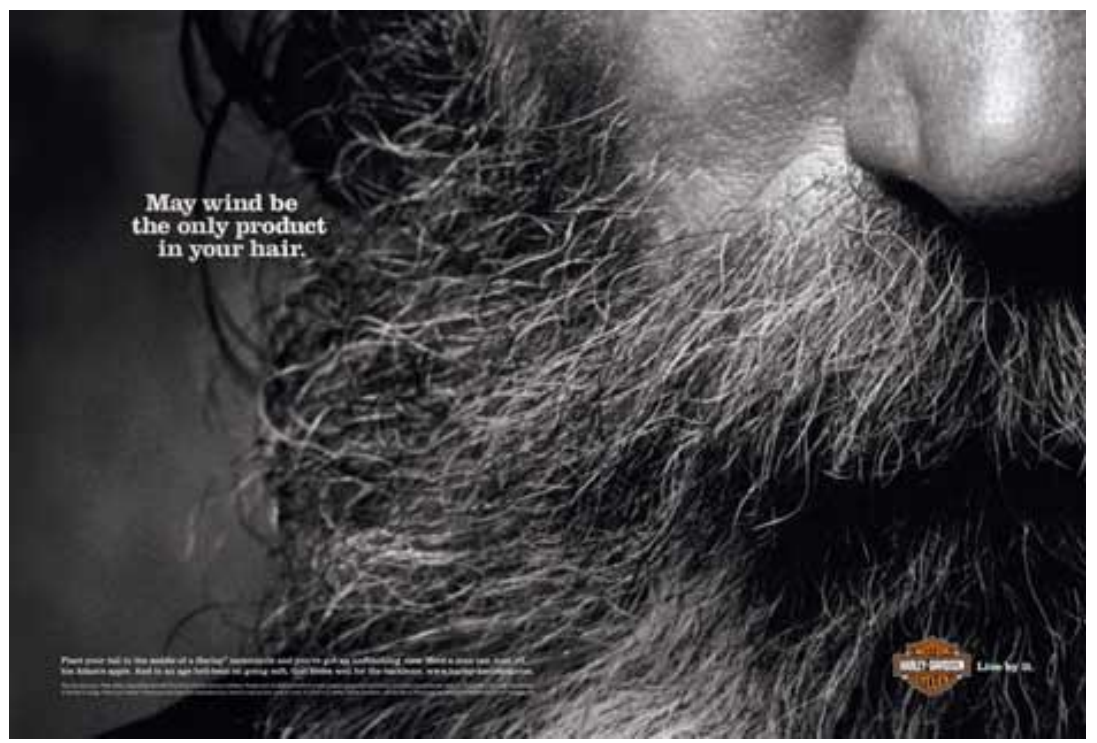

Figura 1 - campanha Harley Davidson - Live by it, 2007. "Que o vento seja o único produto em seu cabelo"

A peça acima faz parte da campanha Live by it, da empresa Harley Davidson, famosa por suas motos de alto padrão. O conceito da campanha vai ao encontro das proposições de Woodward, associando toda uma cultura à comunicação. Mais do que isso, a campanha impulsiona, insere-se e vangloria a identidade de um nicho, os valores que mediam o contato entre indivíduo e sociedade.

Vejamos o segundo exemplo: 


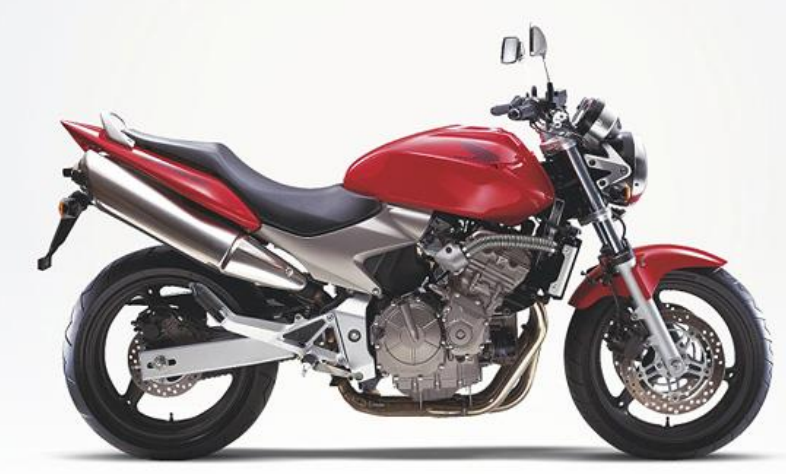

Trazendo para o Brasil toda a moderna tecnologia japonesa, a Honda lança a novíssima CB600F Hornet. Dotada de um 4 cilindros em linha DOHC 16 válvulas de $599 \mathrm{~cm}^{3} \mathrm{com}$ $96 \mathrm{cv}$ de potência, a Hornet mostra que náo veio para brincadeira. E para segurar toda essa força, duplo freio a disco de $296 \mathrm{~mm}$ mordidos por pinças de duplo pistáo na dianteira
e disco simples na traseira. Ressaltando ainda mais a segurança, a Homet conta com o e disco simples na traseira. Ressaltando ainda mais a segurança, a Homet conta com o
exclusivo sistema de protecāo HIS.S - Honda Ignition Security System - que altravés exclusivo sistema de proteção H.IS.S - Honda Ignition Security System - que alraves
de um chip na chave de ignicăa faz uma identificaçáo eletrônica e libera o motor para funcionamento. Interagindo com o piloto, o painel de instrumentos totalmente eletrônico, completo e compacto, oferece multifuncionalidade com conta-giros e relógio digital. E, alimentando a fera, o tanque de 17 litros garante longas aventuras sobre a moto, aliado ao belo design esportivo projetado para oferecer o máximo conforto ao piloto e garupa. Faça já um test-drive, e diga arigatô as outros motos que você já viu.

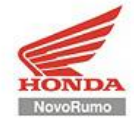

Figura 2 - Campanha Honda - Hornet, 2006.

Fragmento do texto:

"Trazendo para o Brasil toda a moderna tecnologia japonesa, a Honda lança a novíssima CB600F Hornet. Dotada de um 4 cilindros em linha DOHC 16 válvulas de $599 \mathrm{~cm} 3 \mathrm{com} 96 \mathrm{cv}$ de potência [...]”

No exemplo acima, da empresa Honda - também fabricante de motos -, podemos notar enormes diferenças em relação à peça anterior, da Harley Davidson. Fica claro, no trecho transcrito que o anúncio da Honda trabalha com uma comunicação que busca atingir seu consumidor pelo aspecto racional. Ela não cria qualquer vínculo com tribos ou supõe que o consumidor será julgado pelo produto que possui, mas sim fala das 
características do motor e demais aspectos físicos da moto. Tem-se, portanto, um claro exemplo no qual a publicidade reflete e busca construir um processo de identificação, e não de identidade, como no primeiro anúncio.

\section{Conclusão}

Os aprendizados da Teoria das Mediações, de Barbero, ${ }^{14}$ nos mostram que o processo comunicacional só se dá por completo com o alinhamento entre todos os envolvidos: emissor, receptor, meio, mensagem, canal de propagação, resposta e ambiente. Dessa forma, mais uma vez, percebemos a necessidade de levar em consideração características do emissor ao trabalhar na mensagem. O receptor, por outro lado, deve estar preparado para receber essa "roupagem comunicacional", como nos ensina Carrascoza ${ }^{15}$, de forma que ele precisa ter a referência do que está sendo dito antes de estar apto a compreender e absorver aspectos totalmente intangíveis e emocionais compartilhados pela comunicação der um produto e/ou marca. Nesse sentido, a comunicação se mostra como resultado de um processo que envolve inúmeras variáveis, e tendências sempre irão. Porém, o equilíbrio, a visão macro do processo e um estudo aprofundado dos potenciais da empresa e consumidor são imprescindíveis para a diminuição de ruídos e para a eficácia na transmissão de determinada mensagem. Levantar a bandeira sobre qual tom comunicacional é o mais adequado para toda e qualquer situação é um risco, afinal, os elementos do processo constituem um organismo vivo e mutável.

Palavras Chave: marketing, comunicação, publicidade, identidade, identificação 


\section{Referências}

CARRASCOZA, João Anzello. Razão e Sensibilidade no Texto Publicitário. São Paulo: Futura, 2004.

HALL, Stuart. A identidade Cultural na Pós-modernidade. $5^{\text {a }}$ ed. Trad. de Tomaz Tadeu da Silva e Guacira Lopes Louro. Rio de Janeiro: DP\&A, 2001.

KOTLER, Philip. Administração de Marketing: A Edição do Novo Milênio. 10ª ed. São Paulo: Prentice Hall, 2000.

LIPOVETSKY, Gilles. A Felicidade Paradoxal: Ensaio sobre a Sociedade do Hiperconsumo. São Paulo: Cia das Letras, 2006.

MARTIN-BARBERO, Jesus. Dos meios às mediações: Comunicação, Cultura e Hegemonia. Trad. Ronald Polito, Sérgio Alcides. Rio de Janeiro: Editora UFRJ, 1997.

McCARTHY, E. Jerome; PERREAULT Jr, William D. Marketing Essencial: Uma Abordagem Gerencial e Global. São Paulo: Atlas, 1997

NEUMEIER, Marty. The brand gap: How to bridge the distance between business strategy and design. California: New Riders, 2005.

PEIRCE, Charles Sanders. Semiótica. $3^{\text {a }}$ ed. São Paulo: Perspectiva, 2000.

SERRES, Michel. Pertinência e Identidade. In: LÈVY, Pierre, AUTHIER, Michel (orgs.). As árvores de conhecimento. São Paulo: Escuta, 1995.

WITTGENSTEIN, Ludwig J. J. Observações filosóficas. São Paulo: Edições Loyola, 2005.

WOODWARD, Kathryn. Identidade e diferença: uma Introdução Teórica e Conceitual. In: SILVA, Tomaz Tadeu da. Identidade e diferença. A perspectiva dos estudos culturais. Petrópolis: Vozes, 2000.

YANAZE, Mitsuru Higuchi. Gestão de Marketing e Comunicação: Avanços e Aplicações. $2^{\mathrm{a}}$ ed. São Paulo: Saraiva, 2011.

\section{$\underline{\text { SITES }}$}

CANAL HARLEY DAVIDSON. Disponível em:

<http://www.youtube.com/user/harleydavidson?feature=results_main> Acesso em maio/2012.

HONDA. Campanhas. Disponível em: < http://mundodomarketing.com.br/ultimasnoticias/1454/honda-motos-faz-mega-campanha-para-lancar-motocicleta.html> Acesso em maio/2012

O RANKING DOS MAIORES ANUNCIANTES. Disponível em:

$<$ http://veja.abril.com.br/blog/radar-on-line/diversos/o-ranking-dos-maiores-anunciantes-dobrasil/> Acesso em: maio 2012. 